Supplement of Biogeosciences, 12, 5537-5546, 2015

http://www.biogeosciences.net/12/5537/2015/

doi:10.5194/bg-12-5537-2015-supplement

(C) Author(s) 2015. CC Attribution 3.0 License.

(c) (1)

Supplement of

\title{
Responses of soil microbial communities and enzyme activities to nitrogen and phosphorus additions in Chinese fir plantations of subtropical China
}

W. Y. Dong et al.

Correspondence to: X. Y. Zhang (zhangxy@igsnrr.ac.cn)

The copyright of individual parts of the supplement might differ from the CC-BY 3.0 licence. 
Table S1 Seasonal comparison of soil enzyme activities between July and November

\begin{tabular}{|c|c|c|c|c|c|c|}
\hline \multirow{2}{*}{ Treatment } & \multicolumn{2}{|c|}{$\mathrm{G}$} & \multicolumn{2}{|c|}{$\mathrm{NAG}$} & \multicolumn{2}{|c|}{$\mathrm{aP}$} \\
\hline & $\mathrm{t}$ & $\mathrm{P}$ & $\mathrm{t}$ & $\mathrm{P}$ & $\mathrm{t}$ & $\mathrm{P}$ \\
\hline $\mathrm{CK}$ & -10.40 & 0.10 & -6.36 & 0.02 & -7.18 & 0.02 \\
\hline N1 & -10.45 & 0.10 & -8.71 & 0.01 & -12.58 & 0.07 \\
\hline $\mathrm{N} 2$ & -5.40 & 0.03 & -8.92 & 0.01 & -11.71 & 0.01 \\
\hline N1P & -9.64 & 0.01 & -13.80 & 0.01 & -9.31 & 0.01 \\
\hline $\mathrm{N} 2 \mathrm{P}$ & -20.26 & 0.00 & -6.88 & 0.03 & -34.17 & 0.00 \\
\hline $\mathrm{P}$ & -9.95 & 0.01 & -7.54 & 0.02 & -23.57 & 0.00 \\
\hline
\end{tabular}

Note: Results are from paired-sample t-test. 
Table S2. Seasonal comparison of soil microbial community composition between July and November

\begin{tabular}{|c|c|c|c|c|c|c|c|c|c|c|c|c|c|c|c|c|}
\hline \multirow{2}{*}{ Treatment } & \multicolumn{2}{|c|}{ TotPLFAs } & \multicolumn{2}{|c|}{ BacPLFAs } & \multicolumn{2}{|c|}{ FunPLFAs } & \multicolumn{2}{|c|}{ ActPLFAs } & \multicolumn{2}{|c|}{ G+PLFAs } & \multicolumn{2}{|c|}{ G-PLFAs } & \multicolumn{2}{|c|}{$\mathrm{F} / \mathrm{B}$} & \multicolumn{2}{|c|}{$\mathrm{G}+/ \mathrm{G}-$} \\
\hline & $\mathrm{t}$ & $\mathrm{P}$ & $\mathrm{t}$ & $\mathrm{P}$ & $\mathrm{t}$ & $\mathrm{P}$ & $\mathrm{t}$ & $\mathrm{P}$ & $\mathrm{t}$ & $\mathrm{P}$ & $\mathrm{t}$ & $\mathrm{P}$ & $\mathrm{t}$ & $\mathrm{P}$ & $\mathrm{t}$ & $\mathrm{P}$ \\
\hline $\mathrm{CK}$ & -1.23 & 0.06 & -5.25 & 0.03 & 1.39 & 0.30 & -1.45 & 0.28 & -3.47 & 0.07 & -0.55 & 0.64 & -18.77 & 0.01 & -1.80 & 0.21 \\
\hline $\mathrm{N} 1$ & -0.68 & 0.57 & -0.97 & 0.43 & 1.59 & 0.25 & -2.94 & 0.09 & -1.99 & 0.186 & 0.29 & 1.42 & -5.36 & 0.03 & -10.37 & 0.01 \\
\hline $\mathrm{N} 2$ & -1.39 & 0.30 & -0.99 & 0.42 & -0.66 & 0.58 & -0.75 & 0.53 & -1.40 & 0.30 & 0.81 & 0.50 & -10.58 & 0.01 & -0.85 & 0.48 \\
\hline $\mathrm{N} 1 \mathrm{P}$ & -0.96 & 0.44 & -1.89 & 0.19 & 1.57 & 0.26 & -2.42 & 0.14 & -2.55 & 0.13 & 0.77 & 0.52 & -3.96 & 0.06 & -0.59 & 0.62 \\
\hline $\mathrm{N} 2 \mathrm{P}$ & -2.75 & 0.11 & -3.51 & 0.07 & 24.52 & 0.01 & -3.65 & 0.07 & -3.19 & 0.09 & -1.36 & 0.31 & -13.65 & 0.05 & -1.91 & 0.197 \\
\hline $\mathrm{P}$ & -1.45 & 0.28 & -1.71 & 0.30 & 0.038 & 0.97 & -1.61 & 0.25 & -1.87 & 0.20 & -0.89 & 0.47 & -5.11 & 0.04 & -0.97 & 0.44 \\
\hline
\end{tabular}

Note: Results are from paired-sample $t$-test. 